\section{Pacific Northwest}

National Laboratory

Operated by Battelle for the

U.S. Department of Energy

\title{
The Graphite Isotope Ratio Method (GIRM): A Plutonium Production Verification Tool
}

\author{
JP McNeece \\ BD Reid \\ TW Wood
}

January 1999

Prepared for the U.S. Department of Energy under Contract DE-AC06-76RL01830 


\title{
DISCLAIMER
}

This report was prepared as an account of work sponsored by an agency of the United States Government. Neither the United States Government nor any agency thereof, nor Battelle Memorial Institute, nor any of their employees, makes any warranty, express or implied, or assumes any legal liability or responsibility for the accuracy, completeness, or usefulness of any information, apparatus, product, or process disclosed, or represents that its use would not infringe privately owned rights. Reference herein to any specific commercial product, process, or service by trade name, trademark, manufacturer, or otherwise does not necessarily constitute or imply its endorsement, recommendation, or favoring by the United States Government or any agency thereof, or Battelle Memorial Institute. The views and opinions of authors expressed herein do not necessarily state or reflect those of the United States Government or any agency thereof.

\author{
PACIFIC NORTHWEST NATIONAL LABORATORY \\ operated by \\ BATTELLE \\ for the \\ UNITED STATES DEPARTMENT OF ENERGY
}

under Contract DE-AC06-76RL01830

Printed in the United States of America

Available to DOE and DOE contractors from the

Office of Scientific and Technical Information,

P.O. Box 62, Oak Ridge, TN 37831-0062;

ph: (865) 576-8401

fax: (865) 576-5728

email: reports@adonis.osti.gov

\begin{abstract}
Available to the public from the National Technical Information Service, U.S. Department of Commerce, 5285 Port Royal Rd., Springfield, VA 22161 ph: (800) 553-6847 fax: (703) 605-6900

email: orders@ntis.fedworld.gov

online ordering: http://www.ntis.gov/ordering.htm
\end{abstract}

This document was printed on recycled paper.

$(8 / 00)$ 


\title{
The Graphite Isotope Ratio Method (GIRM):
} A Plutonium Production Verification Tool

\author{
J.P. McNeece, B.D. Reid, T.W. Wood \\ Pacific Northwest National Laboratory \\ January 1999
}

The purpose of this document is to provide a simple, concise description of the graphite isotope ratio method (GIRM) for use as a verification tool in estimating a graphite-moderated reactor's total plutonium production. The description covers the theory behind the technique and how the method is actually applied.

\section{Background}

Over the lifetime of a production reactor, neutrons from the fission process not only convert U-238 into plutonium but also bring about changes in the elements of the reactor's core components. Components such as shielding, pressure vessels, coolant piping, control rods, structural supports, and, in the case of graphite moderated reactors, the solid graphite moderator are all affected. Because a reactor's total plutonium production is directly related to total neutron fluence, and, likewise, changes in the elements and isotopes of a reactor's core components are directly related to fluence; it was argued that measuring these changes could provide an accurate estimate of a reactor's total plutonium production. The U.S. Department of Energy funds a project at Pacific Northwest National Laboratory (PNNL) to develop this concept into a practical plutonium production verification tool for graphite moderated reactors. The following sections describe the GIRM project development process.

\section{Identification of Useable Core Components}

The first step was to identify those core components containing the most reliable sources of information about the reactor's operating history. Clearly, only items that remain in place throughout the reactor's lifetime would be useful. Components that have been replaced only provide information about the reactor's production since the time of replacement. Control rods and coolant pipes were routinely replaced, so they were eliminated early on. Shielding materials around the core, while remaining in place, were disqualified due to large spatial variations in the neutron flux (based on measurements from the French $\mathrm{G}-2$ reactor).

It was soon obvious that the most reasonable candidate was the graphite moderator and the impurities known to exist in even the most highly purified reactor-grade graphite. In the known operating experiences of the U.S., U.K., France, and Russia no significant portions (if any) of the graphite moderator were replaced in their large production reactors. 


\section{Identification of Suitable Indicator Elements}

The next step was to identify elements in the graphite that could be used as "indicator" elements, that is, elements that undergo transmutation in a predictable manner due to neutron bombardment. Carbon was ruled out because other sources of carbon are present in the reactor core (nitrogen is converted to carbon when it absorbs a neutron and some reactors use carbon dioxide as a coolant). This left only the graphite impurities as candidate indicator elements. The literature reports a long list of impurities in reactor grade graphite. Examples for several types of reactor grade graphite are given in table 1 (based on early, 1960 era, measurements).

Table 1 - Concentrations of Selected Impurities in Various Hanford Reactor-Grade Graphites (ppm)

\begin{tabular}{|c|c|c|c|c|c|c|c|}
\hline Element & $\begin{array}{c}\text { Detection } \\
\text { Limit }\end{array}$ & KSO & KCF & CSO & CSF & GBF & SGBF \\
\hline $\mathrm{Al}$ & 0.007 & 0.59 & 0.06 & 0.36 & 0.09 & 0.15 & 0.83 \\
\hline $\mathrm{B}$ & 0.005 & 3.0 & 0.08 & 2.8 & 0.13 & 0.04 & 0.10 \\
\hline $\mathrm{Ba}$ & 0.0005 & 2.6 & 0.02 & 2.6 & 0.03 & 0.04 & 0.007 \\
\hline $\mathrm{Ca}$ & 0.002 & 210.0 & 0.13 & 135.0 & 0.27 & 0.59 & 0.22 \\
\hline $\mathrm{Cr}$ & 0.003 & 1.1 & --- & 0.34 & - & 0.005 & - \\
\hline $\mathrm{Cu}$ & 0.001 & 0.68 & 0.15 & 0.19 & 0.28 & 0.06 & 0.68 \\
\hline $\mathrm{Fe}$ & 0.001 & 5.6 & 0.33 & 2.8 & 0.28 & 3.1 & 0.19 \\
\hline $\mathrm{Li}$ & 0.001 & 0.37 & 0.002 & 0.21 & 0.003 & 0.003 & 0.003 \\
\hline $\mathrm{Ni}$ & 0.005 & 0.31 & 0.02 & 2.5 & 0.06 & 0.2 & 0.05 \\
\hline $\mathrm{S}$ & 0.02 & 31.0 & 0.04 & 33.0 & 0.07 & 0.07 & 0.05 \\
\hline $\mathrm{Si}$ & 0.005 & 1.3 & 0.67 & 6.0 & 1.3 & 0.07 & 1.25 \\
\hline $\mathrm{Sr}$ & 0.0005 & 4.0 & 0.003 & 3.1 & 0.002 & 0.008 & --- \\
\hline $\mathrm{Ti}$ & 0.001 & 7.5 & 0.001 & 8.2 & 0.01 & 0.02 & 0.001 \\
\hline $\mathrm{V}$ & 0.001 & 11.0 & - & 12.0 & 0.004 & 0.12 & 0.015 \\
\hline $\mathrm{Zn}$ & 0.001 & 5.4 & 0.06 & 160.0 & 0.16 & 0.08 & 0.43 \\
\hline
\end{tabular}

In addition to the elements listed in table 1, other elements have been recently measured using more sensitive techniques. These additional elements include uranium, chlorine, cobalt, niobium, neodymium, hafnium, tungsten, and rhenium.

A first concept, simply measuring the change in concentration of the impurity elements, was rejected because of the wide variation in the initial concentrations of these impurities. Impurity concentrations in graphite vary from location to location within a single piece of graphite, from one piece to another within a single batch of graphite, from batch to batch for a given manufacturer, and from manufacturer to manufacturer. Therefore, no reliable initial concentration could be established against which to compare the final measured concentration. It became obvious that only by measuring the change in the isotopic ratio of certain irnpurity elements, could an accurate measure of total lifetime neutron fluence be obtained. The use of ratios eliminates the need to know initial concentrations - it is only important to know that the element is present in measurable quantities.

Using isotopic ratios is possible because the initial ratios are fixed by nature (they are not changed by the manufacturing processes except in the case of very light elements such as lithium) and because of differences in the neutron absorption 
cross section of the various isotopes. For example, consider the element boron. As shown in table 1, boron is a common impurity in graphite (albeit very small). Natural boron consists of two isotopes - B-10 and B-11. In nature, the B-10/B-11 isotopic ratio is 0.25 . Only one of these isotopes, $B-10$, has a significant neutron absorption cross section. Therefore, as boron is subjected to neutron irradiation, $\mathrm{B}-10$ is transmuted at a much faster rate than B-11 (B-10 is converted to Li-6 in a neutron-alpha reaction). Figure 1 below illustrates how the $B-10 / B-11$ ratio would change as a function of neutron fluence.

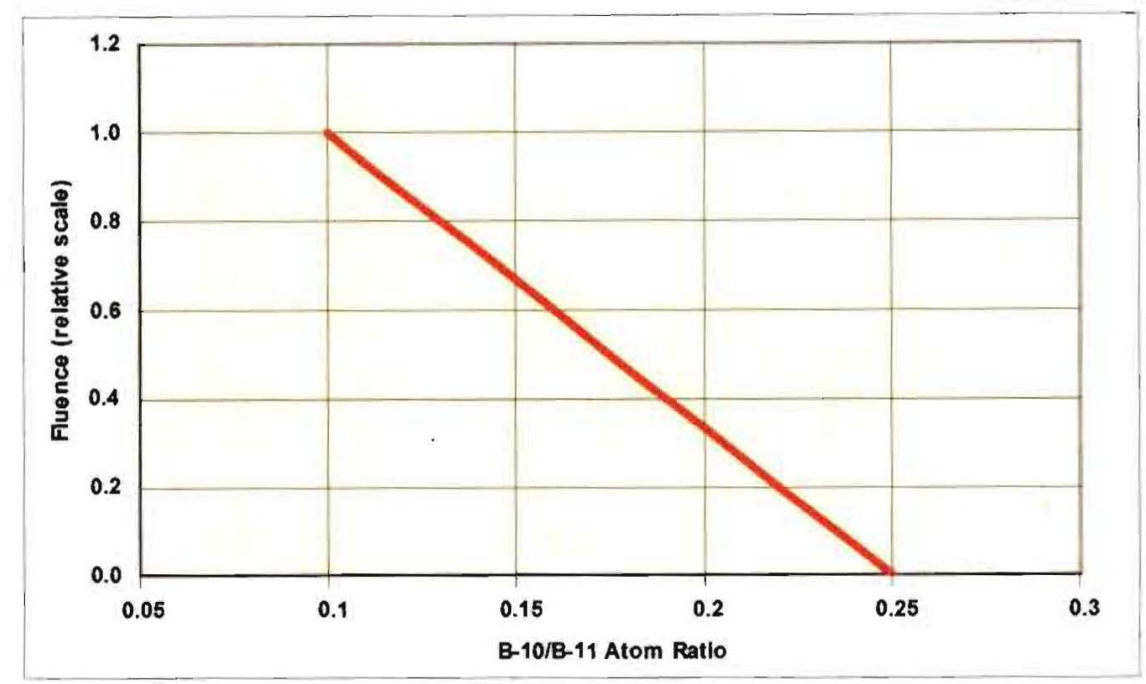

Figure 1 - Change in Boron Isotope Ratios

Therefore, measuring the B-10/B-11 isotopic ratio in a sample of graphite that had been subjected to an unknown neutron fluence and applying the results in figure 1 would give a measure of the actual fluence. There are many other elements that behave in a similar manner. Some are given in table 2. Graphs similar to figure 1 can be generated for all of these.

Table 2 - Isotopes of Indicator Elements

\begin{tabular}{|c|c|}
\hline Element & Isotopes \\
\hline Sulfur & $\mathrm{S}-32, \mathrm{~S}-33$ \\
\hline Chlorine & $\mathrm{Cl}-35, \mathrm{Cl}-36, \mathrm{Cl}-37$ \\
\hline Calcium & $\mathrm{Ca}-40, \mathrm{Ca}-41$ \\
\hline Titanium & $\mathrm{Ti}-48, \mathrm{Ti}-49$ \\
\hline Chromium & $\mathrm{Cr}-50, \mathrm{Cr}-52, \mathrm{Cr}-53, \mathrm{Cr}-54$ \\
\hline Iron & $\mathrm{Fe}-54, \mathrm{~F}-56, \mathrm{Fe}-57, \mathrm{Fe}-58$ \\
\hline Uranium & $\mathrm{C}-235, \mathrm{U}-236, \mathrm{U}-238, \mathrm{Pu}-240, \mathrm{Pu}-241, \mathrm{Pu}-24 \mathrm{Co}-60$ \\
\hline Cobalt & $\mathrm{Nb}-93, \mathrm{Nb}-94$ \\
\hline Niobium & $\mathrm{Nd}-142, \mathrm{Nd}-143$ \\
\hline Neodymium & $\mathrm{Hf}-174, \mathrm{Hf}-176, \mathrm{Hf}-177, \mathrm{Hf}-178, \mathrm{Hf}-179, \mathrm{Hf}-180$ \\
\hline Hafnium & $\mathrm{W}-180, \mathrm{~W}-182, \mathrm{~W}-183, \mathrm{~W}-184, \mathrm{~W}-186$ \\
\hline Tungsten & $\mathrm{Rh}-185, \mathrm{Rh}-187$ \\
\hline Rhenium & $\mathrm{B}-10, \mathrm{~B}-11$ \\
\hline Boron & -
\end{tabular}


Not all the indicator elements identified in table 2 are suitable for all applications. For high power reactors that have operated for many years, isotopes with large neutron absorption cross sections will be completely consumed. Such is the case with boron. Boron-10, with its very large absorption cross section, is reduced below measurable amounts in only a few years in a high power reactor like those at the U.S. Hanford site. Boron, therefore, is more useful for low power reactors, or other reactors that have operated for orly a short time. Choosing a suitable indicator element, therefore, requires a rough idea of the reactor's power level and operating time. Figure 2 shows the effect of reactor operation on the uncertainty of the production estimate for several potential indicator elements.

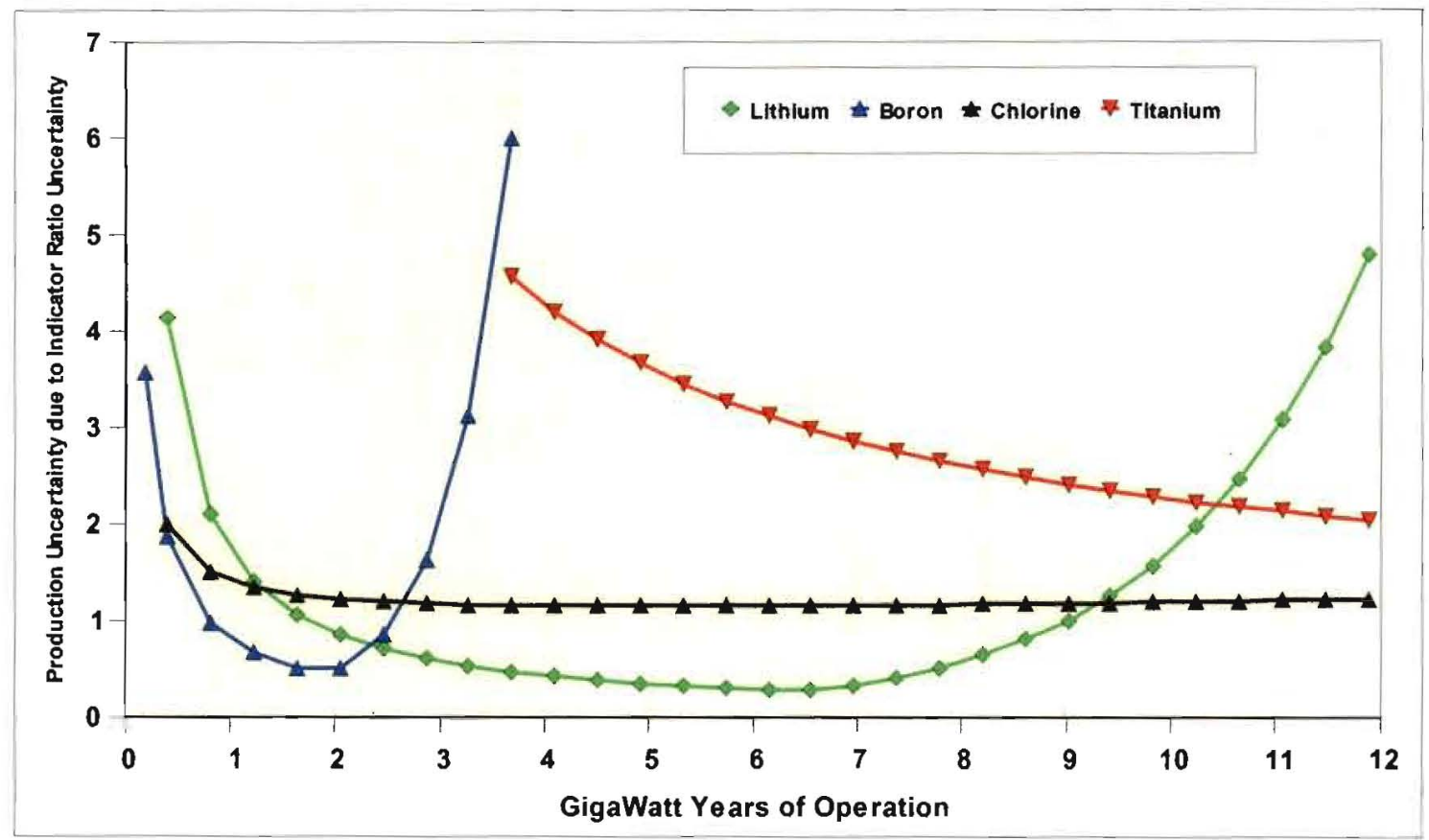

Figure 2 - Production Uncertainty as Affected by Reactor Operation

There are additional, more subtle factors that come into play when selecting a suitable indicator element. Consider the uranium impurity. The major isotopes are $\mathrm{U}-238$ and $\mathrm{U}-235$, both of which undergo transmutation at different rates. In addition, U-236 is produced in about $20 \%$ of the neutron captures in U-235 giving rise to a U-236/U-235 ratio that is initially zero and increases with increasing neutron fluence. (Uranium has long been used as a sensitive neutron fluence indicator. Experimentors place tiny uranium "flux wires" in with their irradiation samples. After the irradiation the flux wires are measured to provide an accurate measurement of the fluence.) Furthermore, U-238 gives rise to plutonium which has four isotopes (Pu-239, Pu-240, Pu-241, and Pu-242) all of which can be measured to give additional estimates of the neutron fluence. Therefore, this one element provides five different isotopic ratios, U-235/U-238, U-236/U-235, Pu240/Pu-239, Pu-241/Pu-239, and Pu-242/Pu-239, from which to make a fluence estimate. 
Experiments have been conducted to demonstrate that analytical techniques are available to perform the measurements described above. In some cases the separation and measurement process is relatively straightforward. In others, most notably boron, the process has yet to be fully demonstrated (separating boron from graphite has proven to be difficult). Work continues on improving the analytical methods.

\section{Full Scale Reactor Application}

With the theory confirmed by experiment, the next step was a full-scale reactor application. An opportunity to apply GIRM was provided by the British who were in the process of decommissioning the Trawsfynydd MAGNOX reactor in Wales. This is a graphite-moderated, $\mathrm{CO}_{2}$ cooled power reactor fueled with natural uranium. They offered to provide graphite samples from the core for demonstration of the GIRM technique. In addition, they provided information on core and fuel design along with fuel cycle data. Information on total plutonium production was withheld until after the application of the graphite isotope ratio had determined the total production. The following discussion describes how the method was applied.

Selecting a suitable indicator element was the first step. Because the reactor operated at relatively high power for a number of years, the most suitable indicator was determined to be titanium. Ninety small graphite samples were taken from known locations throughout the core. All samples were approximately $1 / 2 \mathrm{~cm}$. in diameter by $1 \mathrm{~cm}$. long and were taken in areas adjacent to the fuel as shown in figure 3 .

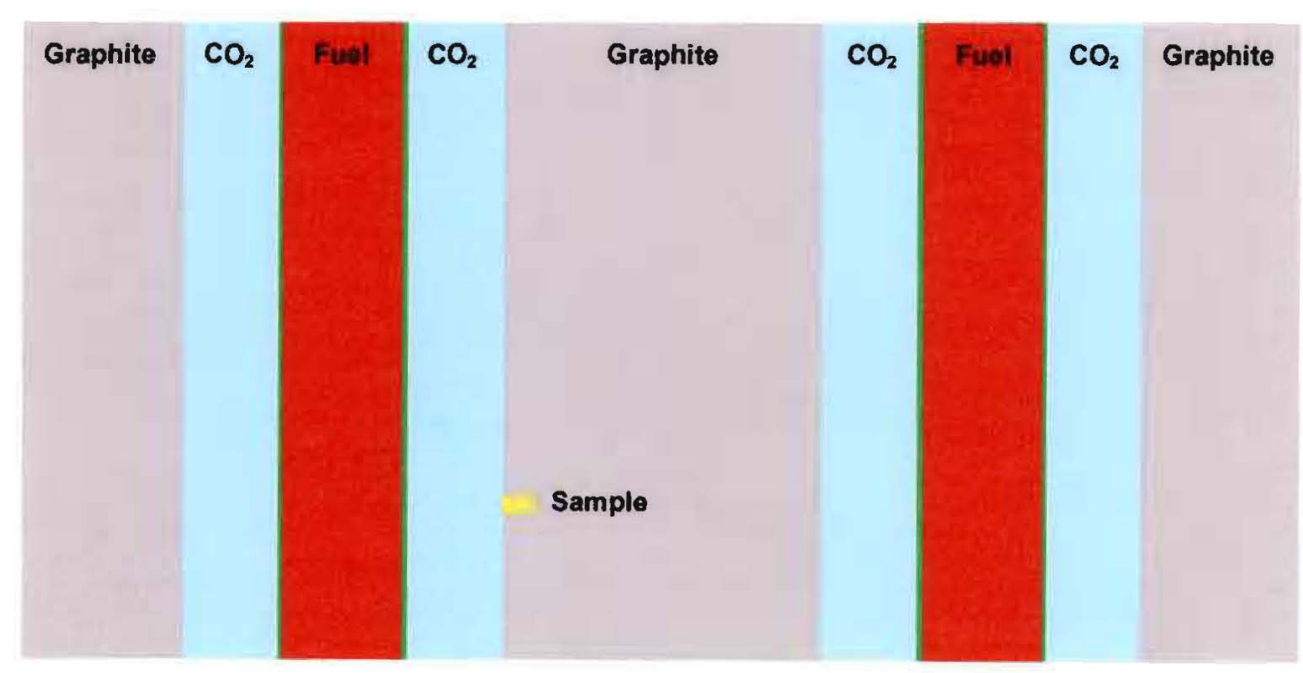

Figure 3 - Sampling Location in MAGNOX Reactor

The samples were shipped to PNNL where the titanium was separated from the graphite and measurements made of the titanium isotopic ratios. While a 
number of isotopes are available, the Ti-49/Ti-48 ratio was deemed the most useful over the fluence range expected in this reactor. (The details of the analytical procedures for separating and measuring the isotopic ratios will not be discussed. It is sufficient to state that the process is well developed and resulted in measured ratios with small errors. Other documents are available that discuss the measurement techniques in detail.)

In the foregoing discussion, the emphasis was on using the isotopic ratio to give an estimate of the neutron fluence from which an estimate of plutonium production could be made. In applying the method to a full-scale reactor where details of fuel and core design are known, a more direct correlation can be made between changes in isotopic ratio and plutonium production. Using reactor physics models of the fuel and moderator geometry, calculations can be made that relate changes in isotope ratio to plutonium production in fuel located adjacent to the sample location. So, instead of having a correlation like that shown in figure 1 which relates isotope ratio to fluence, the result is a correlation like that shown in figure 4 which relates isotope ratio to plutonium production (in terms of grams of plutonium/unit length of fuel).

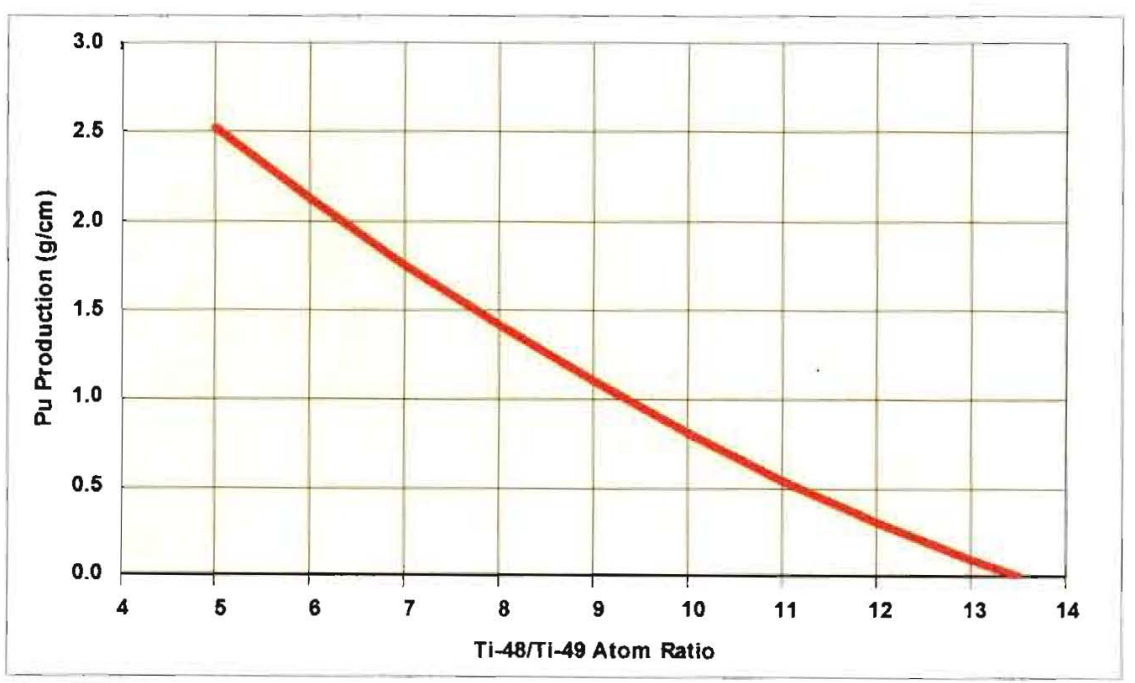

Figure 4 - Plutonium Production Correlation for Trawsfynydd Reactor

The final step in computing the total production was to use the results from the 90 sampling locations to produce a reactor volume weighted average plutonium production per $\mathrm{cm}$ of fuel length which, when multiplied by the total fuel length, gives the total plutonium production. Computing an average value from a number of samples taken over the reactor volume is necessary due to the spatial variation of the neutron flux (and, thus, plutonium production). Due to neutron leakage from all the reactor surfaces, the flux profile is peaked in center and falls off in a roughly cosine shape to the reactor edges (it is not zero at the edge but it is roughly a factor of four lower than at the center). 
Aggregating the 90 local plutonium/cm values into a reactor average value was accomplished by performing a regression analysis of the values (complete with error propagation). The regression analysis utilized a functional fit to a set of cosine functions. (The details of the regression analysis are not included in this discussion. It is sufficient to state that the method is based on sound statistical principles and the results provide an accurate measure of the total reactor production rate in grams of plutonium $/ \mathrm{cm}$ of fuel length. Other documents are available that describe the regression method in detail.)

Comparing the result of multiplying the total fuel length by the average linear production gave a total reactor plutonium production for Trawsfynydd that agreed within the uncertainty range of the value provided by the operator (based on records of fuel reprocessing for this reactor).

This full-scale reactor experiment provided proof that GIRM is a viable tool for use in validating plutonium production in graphite moderated reactors.

\section{Future Directions}

GIRM development is not fully completed. While the full-scale reactor test demonstrated the method's applicability to high fluence reactors, more work is needed to make the method useable over a broader range. Analytical techniques have been developed for only a small suite of the potential indicator elements. For application over a broader range of reactors, analytical techniques will need to be developed for additional indicators. To date, no single technique is applicable for more than one indicator element. Each will require its own unique separations and measurement process.

Improvements can be made in the analytical techniques required to obtain the isotope ratio values. Presently, the technique involves laborious wet chemistry techniques to separate the indicator element from the graphite matrix. The separated material is then loaded into a high sensitivity mass spectrometer for the ratio measurement. New state-of-the-art mass spectrometers are becoming available that offer the promise of in situ measurement of the isotope ratios (that is, separating the indicator from the graphite matrix would not be required) which would eliminate much of the expense and effort required to make the ratio measurements. Further investigations using such instruments is planned. 